diagnosis should allow more accurate parental counseling and more effective long-term treatment.

\title{
ABORTED AND REFRACTORY STATUS EPILEPTICUS COMPARED
}

Clinical and EEG characteristics, etiologies, treatment response, and predictors of long-term outcome were determined in 154 children with status epilepticus (SE) hospitalized at the Mayo Clinic, Rochester, MN, 1994-2004. Patients with status aborted with medication (ASE) in $69 \%$ were compared to $39 \%$ with refractory SE (RSE). SE was defined as continuous tonic-clonic or electrographic seizure activity for at least $10 \mathrm{~min}$ or intermittent seizure activity without recovery of consciousness for at least $30 \mathrm{~min}$. (Mayer SA et al. Arch Neurol 2002;59:205-210). Etiology of SE was acute symptomatic in 26\%, remote symptomatic $35 \%$, idiopathic $20 \%$, and febrile in $10 \%$. RSE compared to ASE was significantly associated with a higher family history of seizures, higher number of seizures and AEDs, nonconvulsive SE, and focal or electrographic seizures on initial EEG. In-hospital mortality was significantly higher with RSE $(13.3 \%)$ than ASE $(2.1 \%)$. RSE patients developed more neurological deficits and more epilepsy at long-term follow-up than ASE children. More aggressive treatment resulted in better responses and outcomes. Poor outcome risk factors included long seizure duration, acute symptomatic etiology, nonconvulsive SE, and young age ( $<5$ years) at admission. Prospective, randomized trials of different treatment protocols are advocated. (Lambrechtsen FACP, Buchhalter JR. Aborted and refractory status epilepticus in children: a comparative analysis. Epilepsia 2008;49(4):615-625). (Respond: Jeffrey R Buchhalter MD, Phoenix Children's Hospital, 1919 E Thomas Road, Phoenix, AZ 85016).

COMMENT. Status epilepticus in children is refractory in $40 \%$, and RSE is related to family history, number of seizures and AEDs, nonconvulsive status, and initial EEG abnormalities. Etiology is an important determinant of outcome, especially acute symptomatic causes. Identification of these risk factors should lead to more aggressive therapy and better outcome.

\section{INFECTIOUS DISORDERS}

\section{HERPES SIMPLEX VIRUS-1 AND BELL'S PALSY}

The association between herpes simplex virus-1 (HSV-1) infection and Bell palsy was determined in 47 children studied at Children's Hospital at Montefiore, Bronx, NY. Swabs of saliva and conjunctiva were taken for PCR testing. To validate PCR testing, swabs were obtained from patients with oral lesions of herpes gingivostomatitis. An HSV-1 enzyme-linked immunosorbent assay was positive in 33 of 42 affected patients compared to 16 of 41 controls $(\mathrm{P}=0.0003)$. HSV-1 polymerase chain reaction was positive in 10 of 47 affected patients compared to 4 of 45 controls $(\mathrm{P}=0.08)$. The findings support an association between HSV-1 infection and Bell palsy in children. (Khine H, Mayers M, Avner JR, Fox A, Herold B, Goldman DL. Association between herpes simplex virus-1 infection and idiopathic unilateral facial paralysis in children and adolescents. Pediatr Infect Dis J May 